\title{
Correction to: "Preparation and Anticorrosive Properties of Oligoaniline Modified Silica Coatings "[Int. J. Electrochem. Sci., 12 (2017) 9944 - 9957; doi: 10.20964/2017.11.11]
}

Yuwei Ye ${ }^{1,2}$, Wei Liu ${ }^{1}$, Zhiyong Liu ${ }^{1}$, Haichao Zhao ${ }^{2 *}$, Liping Wang ${ }^{2 *}$

${ }^{1}$ Corrosion \& Protection Centre, University of Science \& Technology Beijing, Beijing 100083, China

${ }^{2}$ Key Laboratory of Marine Materials and Related Technology, Zhejiang Key Laboratory of Marine Materials and Protective Technologies, Ningbo Institute of Materials Technology \& Engineering, Chinese Academy of Sciences, Ningbo, 315201, China

*E-mail: zhaohaichao@nimte.ac.cn, wangliping@nimte.ac.cn

Received: 8 February 2021 / Published: 28 February 2021

The authors regret that there were errors in the original published version.

There was an inadvertent error in Figs. 4c, 4d, 11c and 11d. In order to improve the accuracy of the paper, the corrected Figs. 4c, 4d, 11c and 11d as a replacement of the already published Figs. 4c, 4d, 11c and $11 \mathrm{~d}$ are as follows. That should be corrected. The modified part has no effect on the results and conclusion of the article. The authors would like to apologize for any inconvenience caused.

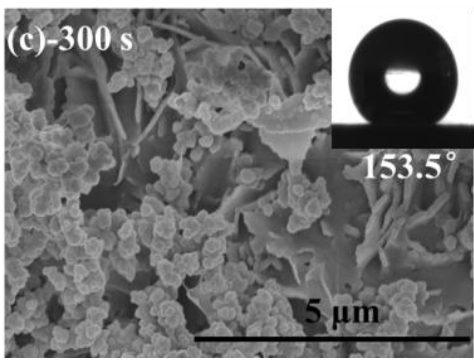

Fig.4c

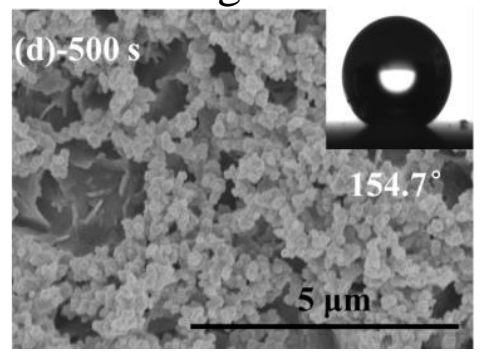

Fig.4d 


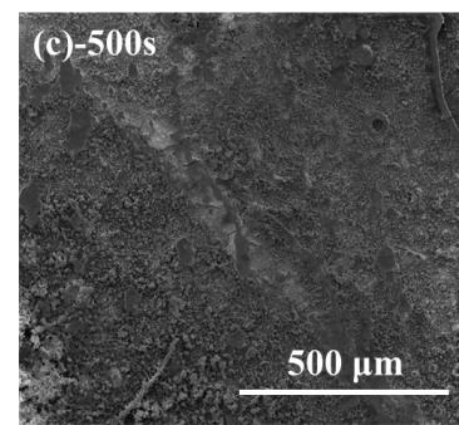

\section{Fig.11c}

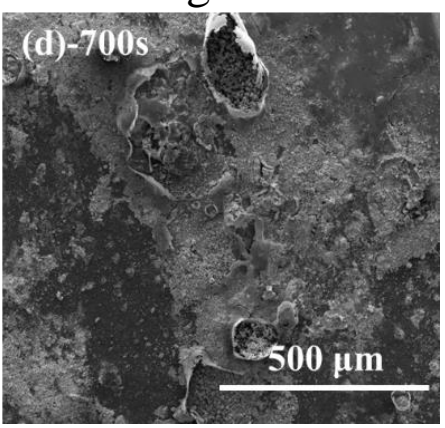

Fig. 11d

(C) 2021 The Authors. Published by ESG (www.electrochemsci.org). This article is an open access article distributed under the terms and conditions of the Creative Commons Attribution license (http://creativecommons.org/licenses/by/4.0/). 